As a Type II $a$ Pearson curve was found to be the best-fitting curve for the observed distribution of tetrads, with $\sigma_{t}=0.031$ (curve $A$ ), similar Pearson curves have been drawn corresponding to the Two Factor Theory, with $\bar{\sigma}_{t}=0.028 \pm 0.0026$ (curve $B$ ), and to the Sampling Theory, with $\sigma_{t}=0.059$ (curve $C)$. It can be seen by inspection which of the two curves, $B$ or $C$, approximates more to curve $A$.

Further evidence against the applicability of the Sampling Theory to our data is given if we assume the truth of this theory (with Mackie's equations), and set out from the observed value of $\sigma_{t}$, that is, $0 \cdot 031$.

$$
\begin{aligned}
\text { Since } \sigma_{t} & =0 \cdot 463 / \sqrt{ } N \\
\therefore \sqrt{ } N & =15, \text { and } N=225 \\
\therefore \quad \sigma_{r} & =\sqrt{1-\left(\frac{2}{\pi}\right)^{2}} / \sqrt{ } N \\
& =0.051,
\end{aligned}
$$

whereas the observed value of $\sigma_{r}$ is 0.087 .

William Brown.

Psychological Department, Oxford.

March 21.

${ }^{1}$ Brown, W., and Stephenson, W., "A Test of the Theory of Two Factors", Brit. J. Psychol., 23, Part 4, April 1933. Also NATURE, 130, 588, Oct. 15,1932

'Spearman, C. "The Abilities of Man", London, 1927, pp. 74, 75.

"Spearman, C., "The Abilities of Man", London, 1927, pp. 74, 75. rinomson, Grodrey H., Proc. "Roy. Soc., A, 95, 400, 1919. Also Brown, W., and Thomson, G. H., "Essentials of Mental

"Mackie, John, "Mathematical Consequences of Certain Theories of Mental Ability", Proc. Roy. Soc. Ed., 49, Pt. 1, No. 2, Feb. 1929.

\section{Water Supplies and Emergency Legislation}

When we wish to determine the relation between the rain falling on an area, and the volume of water delivered by the stream draining that area, we are faced with a problem as yet unsolved. The geological, physical and meteorological conditions of river catchment basins are so varied that a search for a mathematical expression connecting 'yield' from rainfall appears to be in vain.

The simplest and most accurate method for such determination is, as suggested in the leading article in Nature of April 28, by the actual measurement of stream flow for a considerable number of years, so as to ascertain the mean, the maximum, and the minimum flow that may be expected; and also the variation of stream flow during the seasons of the year. Comparing the results so obtained with the rainfall during those years, we may be able to deduce with some reasonable accuracy stream flow in years in which rainfall records are available, and stream flow gaugings are not.

Observation of stream flow in Great Britain have been neglected, and the same remark applies to observation of water levels in our wells. Some years ago the British Association laid down a series of questions in regard to wells which appear to have been lost sight of. It is possible that the limited funds allotted for investigations of this nature curtailed the information collected.

The heavy rains of 1927 , the disaster of January 1928 , and the following wet years caused the country to be more concerned with floods and arterial drainage, than with drought; leading to the appointment of the Royal Commission of 1927, and the passing of the Drainage Act of 1930 , and so to the formation of Catchment Boards, with the result that schemes for widening and deepening our rivers and carrying off the rainfall as quickly as possible are under considera. tion.

Speculative building on riparian lands subject in former years to flooding at very long intervals, are now more frequently flooded, due to the increased flow from drainage of lands, permeable areas and arterial roads, and this has increased the demand for a more rapid carrying away of flow due to rainfall.

The problem that now faces the country is the preservation of our springs. Most of our rivers derive their dry weather flow from springs, the only source of supply of which is the percolation of our winter rains to the ground water plane of saturation; and instead of widening and deepening our rivers to pass off extraordinary floods quickly, the flood water should be allowed to spill over the river margins so that as the flood slowly subsides, the water is enabled to percolate into the subsoil. One other suggestion I would make, is a return to Mr. Joseph Elkington's 'sink hole drainage'. That is, instead of passing off rain-water from whatever sources it may be received into streams and thus swell our rivers, it is passed into 'soakage pits' or 'absorbing wells' placed at suitable intervals and sunk to permeable areas, and thus to pass the rainfall to ground storage.

The Catchment Boards, I would suggest, should now confine their activities to the measurement of stream flow and its correlation with rainfall; to carry out the requirements of the British Association in regard to riparian lands subject to periodic flooding, so as to reserve them for pasture or agriculture, and to prevent speculative building thereon.

Flat 3,

J. M. LACEY.

60 Hamilton Terrace,

N.W.8.

April 27.

\section{Factors Controlling Moulting and 'Metamorphosis' in an Insect}

Is the blood-sucking bug, Rhodnius prolixus, moulting occurs at a definite interval after feeding; only one meal being necessary in each stage. The morphological changes at moulting are relatively slight; save at the fifth moult, when the insect becomes adult ${ }^{1}$. It is therefore convenient (without prejudice to questions of homology) to refer to this final moult as 'metamorphosis'. In this last stage, the interval between feeding and moulting averages twenty-eight days. If its head is removed soon after feeding, the insect will not moult-although some of these headless individuals have remained alive more than eleven months. But there is a 'critical period', about seven days after feeding, after which moulting is no longer prevented by decapitation. If the blood from an insect decapitated after this critical period is allowed to circulate in an insect decapitated before this period, the latter is caused to moult. Clearly, a 'moulting hormone' is present ; and it is probably secreted in the head. Of the organs in the head, the only one which shows distinet changes during this period is the corpus allatum, the cells of which swell up to a maximum at about the seventh day after feeding, and then diminish. Perhaps this is the source of the moulting hormone--though the evidence on this point is still incomplete.

Similar results have been obtained with the earlier nymphs. But if the blood from a 5th or final nymph decapitated after the critical period is allowed 